\title{
Aerobic and Anaerobic Endurance of Disabled Swimmers in Special Preparation Sub-Period
}

\author{
Authors' Contribution: \\ A - Study Design \\ B - Data Collection \\ C - Statistical Analysis \\ D - Data Interpretation \\ E - Manuscript Preparation \\ $F$ - Literature Search \\ Rafał Szafraniec $^{1}(\mathrm{~A}, \mathrm{C}, \mathrm{D}, \mathrm{E})$, Wojciech Seidel ${ }^{1}$ (A,D ,E), \\ Dawid Kruszyna $^{1(B, F)}$, Anna Żurowska ${ }^{2}$ (B, F) \\ ${ }^{1}$ University School of Physical Education in Wroclaw, Poland \\ ${ }^{2}$ The Angelus Silesius State School of Higher Vocational Education in Walbrzych, \\ Poland
}

$G$ - Funds Collection
Key words: aerobic endurance, anaerobic endurance, disabled swimming, macrocycle

Material/Methods: The study included 12 disabled swimmers from a section of the Polish Sports Association for the Disabled "START" Wroclaw. Two standardized tests were used. The T30 test was used to evaluate aerobic endurance and the $6 \times 50 \mathrm{~m}$ test was applied to estimate anaerobic endurance. For all analyzed parameters the median, first (Q1) and third (Q3) quartiles were calculated. To determine the significance of differences between the results obtained in the preliminary and the control test, the nonparametric Wilcoxon test for dependent samples was used. Statistical significance was considered at $p \leq 0.05$.

Results: Total distance median in the T-30 test (DST1 $=1575.5 \mathrm{~m}$ vs DST2 $=1650 \mathrm{~m}$ ) improved in a statistically significant way $(p=0.02)$. Analyzing the results obtained in the entire group of athletes in the $6 \times 50 \mathrm{~m}$ test, for each single section of $50 \mathrm{~m}$, it was observed that the swimming time was significantly shorter during the second study $(p<0.05)$ but the first section of 50 meters.

Conclusions: In a sub-period of special preparation both aerobic and anaerobic endurance of disabled swimmers improved. A more significant improvement was observed in terms of anaerobic endurance, as it occurred for all swimmers. The $T-30$ and $6 \times 50 \mathrm{~m}$ tests proved to be a sensitive tool for assessing aerobic and anaerobic endurance of swimmers with disabilities.

Word count: 2748

Tables: 2

Figures: 2

References: 30

Corresponding author:

Rafał Szafraniec Ph.D.

University School of Physical Education

Dep. of Disability Sport

al. I.J. Paderewskiego 35, bud. P4 pok. 2/48

51-612 Wrockaw

Phone/ Fax: 0713473568

E-mail: rafal.szafraniec@awf.wroc.pl
Received: May 2012

Accepted: September 2012

Published: December 2012 


\section{Introduction}

The level of sports swimming of people with disabilities both in Poland and abroad in recent years has significantly increased, and at present it is not just a form of rehabilitation, but rather a high-performance sport. Continuous development of disabled people's swimming as a Paralympic discipline, ever stronger competition and greater progress of results, requires constant monitoring and customization of training [1]. Elite performance in competitive swimming requires superior aerobic and anaerobic conditioning as well as great technical expertise that takes years to develop [2]. The percentage contribution of aerobic and anaerobic energy sources to the total energy expenditure in swimming was shown to be independent of the swimming style, gender or skill and is essentially dependent upon the duration of the exercise [3]. The percentage contribution of anaerobic alactic (AnAl), anaerobic lactic (Anl) and aerobic (Aer) energy sources to the overall energy expenditure during maximal swimming trials in the crawl amounts to: at the $50 \mathrm{~m}$ distance AnAl 26\%, Anl 59\%, Aer 15\%; at the $100 \mathrm{~m}$ distance AnAl 20\%, Anl 47\%, Aer $33 \%$; at the $200 \mathrm{~m}$ distance AnAl 14\%, Anl 24\%, Aer 62\% [4]. The exercise duration is indeed the major determinant of the energy source to be exploited in all forms of locomotion [5]. Constant monitoring of physiological changes in the parameters defining the aerobic and anaerobic endurance is necessary for the ongoing evaluation and modification of the training process [6]. This is of particular importance for disabled swimmers, whose training loads should be individually adjusted to their capabilities. Describing the preparation of the British Paralympic team in swimming, Pheasey points to the need for regional testing within the swimmers' home-based training program on a 6-8-week basis, with the participation of the swimmer's home-based coach and physiologist [7].

The level of general and specific endurance should vary depending on the sub-period of preparation. The period of targeted preparation [8] also known as the period of specific endurance [9] should develop anaerobic endurance above all [10,11].

The purpose of the study was to investigate whether, in addition to an expected increase in anaerobic endurance, aerobic endurance of disabled swimmers in special preparation sub-period would also improve. Furthermore, the decision was made to examine whether the applied tests prove sufficiently sensitive for swimmers with disabilities as well.

\section{Material and Methods}

The study included 12 disabled swimmers from a section of the Polish Sports Association for Disabled "START" Wroclaw. The mean age was $17.6 \pm 4.9$ years and average training duration 5.3 \pm 2.2 years. Respondents were characterized by different locomotor and visual dysfunctions that resulted in different functional capabilities in the water. However, the swimmers' athletic level was similar - everyone was a medalist at the Polish Junior Championships. The study was conducted on a 25-meter indoor swimming pool of the University School of Physical Education in Wroclaw. Each time the tests were conducted in the same temperature of water and air. The first study was conducted in mid-January 2010 - at the beginning of a special preparation sub-period of a sixmonth macrocycle preparing athletes to compete in the Winter Polish Championships in Swimming for Athletes with Disabilities. The second series of tests was repeated six weeks later, in late February of 2010 - at the end of a special preparation sub-period of the same macrocycle. During this time, they underwent six workouts a week. A significant portion of each training unit was the warm-up, warm-down and loose swimming between the main tasks performed at higher intensity. The beginning of the sub-period was dominated by loads which were aimed at improving aerobic capacity. They consisted of swimming at or slightly above the anaerobic threshold. Maximal efforts played a gradually increasing role. Greater energy consumption came from mixed and anaerobic transformations. Training in this sub-period was clearly set to improve the capabilities needed to achieve the best result in the competition. Much attention was devoted to the techniques improvement and optimization in order to enhance the quality of motor habits (the form and structure of movement), which are the basis for development of speed events, and work out the most economical technique of motion which leads to an increase in special endurance. 
Prior to both tests, the competitors underwent a 15-minute warm-up on shore and about a 20minute warm-up in water (strictly according to instructions given by the coach) - just as they do before every workout.

In order to determine the level of aerobic endurance the T-30 test was used, which consisted in covering the longest distance in freestyle (recorded with an accuracy of $1 \mathrm{~m}$ ) in 30 minutes. In this test, the total distance (DST) was analyzed, and also for training purposes, the average time to swim 50 meters was calculated [12]. The athletes were deployed individually on the track and took off from water by the pushing away from the wall on the sound signal (whistle). Respondents were informed of the elapsed time also by the sound signal after ten and twenty minutes from the start. The end of the test period was announced by a loud double signal (whistle). Then the swimmers stayed in place until the researcher determined their position with a measuring tape with an accuracy of 1 meter from the wall of one end of the pool. The result was recorded on the form.

To estimate anaerobic endurance the $6 \times 50 \mathrm{~m}$ freestyle test was applied. This test assesses competitors' ability to keep the race-pace during interval swimming. This test is commonly used to evaluate the swimmers' preparation for competition, and indirectly provides information about glycolytic power and endurance. During the test, an athlete covers distances of 50 meters six times with his best style, at the maximum speed. Starts to all sections were made from water after pushing away from the wall, and the time of covering every 50 meters was recorded using a stopwatch accurate to 0.01 seconds. Recovery breaks between repetitions were 30 seconds long [13]. We analyzed the average time (Tavg) recorded during the six trials and the time of covering a single section.

In statistical analysis we calculated the percentage difference between the parameter values obtained in both tests according to the formula below:

$$
\Delta \mathrm{P}=\frac{\mathrm{P} 2-\mathrm{P} 1}{\mathrm{P} 1} \cdot 100 \%
$$

$\mathrm{P} 1$ - value of the parameter obtained in test No. 1

P2 - value of the parameter obtained in test No. 2

$\Delta \mathrm{P}$ - the percentage difference between the parameter values obtained in both tests in relation to the group

$\delta \mathrm{P}-$ the percentage difference between the parameter values obtained in both tests in relation to a single swimmer.

The nonparametric Wilcoxon test for dependent samples was used to determine the significance of differences between the results obtained in the preliminary and the control test. Statistical significance was considered at $p \leq 0.05$. All calculations were performed using the computer program Statistica, ver. 9.0 (StatSoft).

\section{Results}

\section{Aerobic Endurance}

Changes in the level of aerobic endurance were expressed as the percentage difference in the total distance ( $\delta$ DST) covered by swimmers in the T-30 test during the first and the second attempt.

A positive value of the difference ( $\delta$ DST) indicated improved aerobic endurance, and the negative one - its deterioration during the analyzed period of the macrocycle. At the end of the special preparation sub-period 10 disabled athletes covered a longer distance, and two - a shorter one compared to the beginning of this sub-period (Fig.1). The greatest progress was seen in athlete No. 8, who improved his score by over $11 \%$ (DST1 $=1520 \mathrm{~m}$ vs. DST2 $=1690 \mathrm{~m}$ ). The largest deterioration of the result (almost by $3 \%$ ) was found in swimmer No. 4 (DST1 = $2085 \mathrm{~m}$ vs. DST2 = $2025 \mathrm{~m}$ ).

It can therefore be concluded that the level of aerobic endurance of disabled athletes who practice swimming was higher at the end of the sub-period of special preparation, as confirmed by 
statistical analysis which showed that the increase in the total distance covered during the second trial was statistically significant at $p=0.02$ (Tab. 1).

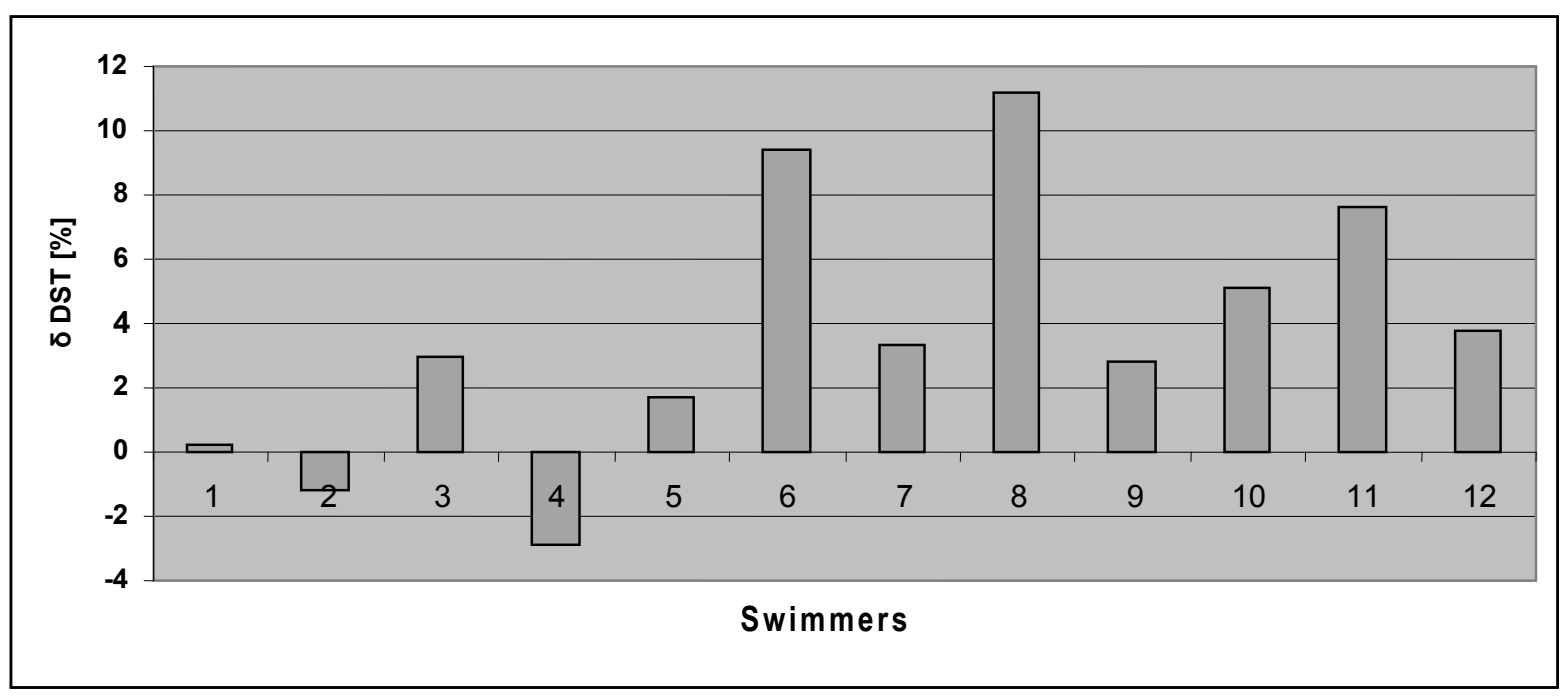

Fig. 1. The percentage differences in the total distance ( $\delta$ DST) covered during the T-30 test between study 2 and study 1

Tab. 1. Distance (DST) covered in the T-30 test in both studies; Q1 - first quartile, Q3 - third quartile, $\triangle$ DSTavg - percentage difference of average DST between the second and the first attempt, $p$ - level of statistical significance in the Wilcoxon test

\begin{tabular}{|c|c|c|c|c|c|c|c|}
\hline & Median & Max. & Min. & Q1 & Q3 & $\begin{array}{c}\Delta \text { DSTavg } \\
{[\%]}\end{array}$ & $\mathbf{p}$ \\
\hline DST 1 [m] & 1575.5 & 2130.0 & 900.0 & 1121.0 & 1902.5 & 3.7 & 0.02 \\
\hline DST 2 [m] & 1650.0 & 2210.0 & 915.0 & 1182.5 & 1982.5 & 3.5 \\
\hline
\end{tabular}

\section{Anaerobic Endurance}

Changes in the level of anaerobic endurance between the first and second attempt were also presented in percentage values $-\delta$ Tavg (Fig. 2). Negative percentage difference in the average time ( $\delta \mathrm{Tavg})$ to swim 50-meter sections between the second and the first attempt meant that the athlete covered the distance in a shorter time and thus was characterized by a higher speed of swimming. During the sub-period of special preparation all athletes improved the average time (Tavg) to swim a section of $50 \mathrm{~m}$. The greatest progress was seen again in athlete No. 8, who improved his score by over $5 \%$ (Tavg1 $=43.03 \mathrm{~s}$ vs. Tavg2 $=40.73 \mathrm{~s}$ ). The smallest improvement of Tavg was observed in swimmer No. 6 - only by $0.2 \%$ (Tavg1 = $37.67 \mathrm{~s}$ vs. Tavg2 = $37.58 \mathrm{~s}$ ).

Analyzing the results obtained in the entire group of athletes, for each single section of $50 \mathrm{~m}$, it was observed that the swimming time was significantly shorter during the second study $(p<0.05)$ but the first section of 50meters (Tab. 2). The greatest improvement was observed in the result of the 5th section, where the average time ( $\Delta$ Tavg) obtained by the whole group in the second study was about $3.9 \%$ shorter compared to the first test $(p=0.002)$. This demonstrates the improvement of anaerobic endurance during this sub-period. 


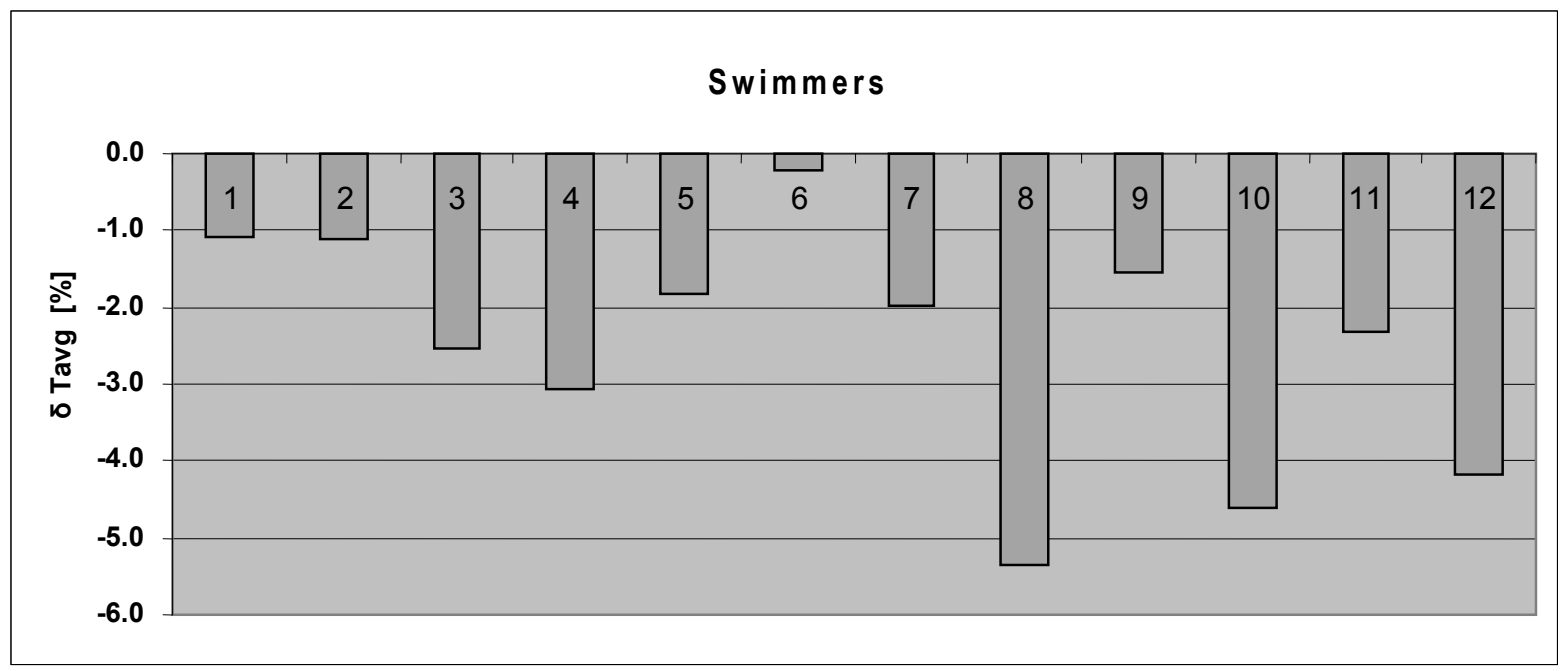

Fig. 2. The percentage differences in the average time ( $\delta$ Tavg) to swim 50 -meter sections in the $6 \times 50 \mathrm{~m}$ test between study 2 and study 1 .

Tab. 2. Time $(T)$ to swim every $50 \mathrm{~m}$ in the test of $6 \times 50 \mathrm{~m}$ in both trials; $\mathrm{Q} 1$ - first quartile, $\mathrm{Q} 3$ - third quartile, $\Delta$ Tavg - percentage difference in average time to swim a 50-meter section between the second and the first attempt, $\mathrm{p}$ - level of statistical significance in the Wilcoxon test; NS - not significant

\begin{tabular}{|c|c|c|c|c|c|c|c|}
\hline $\mathrm{T}[\mathrm{s}]$ & Median & Max. & Min. & Q1 & Q3 & $\Delta$ Tavg $[\%]$ & $p$ \\
\hline 1st 50m T1 [s] & 42.73 & 84.27 & 31.42 & 36.30 & 66.38 & \multirow{2}{*}{-0.8} & \multirow{2}{*}{ NS } \\
\hline $1 \mathrm{st} 50 \mathrm{~m} \mathrm{T2}[\mathrm{s}]$ & 41.64 & 83.45 & 32.67 & 36.53 & 65.85 & & \\
\hline 2nd $50 \mathrm{~m} \mathrm{T1}[\mathrm{s}]$ & 43.68 & 86.17 & 34.71 & 38.14 & 68.09 & \multirow{2}{*}{-1.3} & \multirow{2}{*}{0.03} \\
\hline 2nd 50m T2 [s] & 43.44 & 85.09 & 33.82 & 37.02 & 67.74 & & \\
\hline $3 \mathrm{rd} \mathrm{50m} \mathrm{T1} \mathrm{[s]}$ & 45.49 & 87.38 & 35.01 & 38.40 & 68.93 & \multirow{2}{*}{-2.7} & \multirow{2}{*}{0.004} \\
\hline $3 \mathrm{rd} \mathrm{50m} \mathrm{T2} \mathrm{[s]}$ & 43.94 & 84.67 & 33.54 & 38.00 & 66.60 & & \\
\hline 4th $50 \mathrm{~m} \mathrm{~T} 1$ [s] & 46.07 & 87.93 & 34.72 & 38.79 & 69.15 & \multirow{2}{*}{-2.8} & \multirow{2}{*}{0.002} \\
\hline 4th $50 \mathrm{~m} \mathrm{~T} 2[\mathrm{~s}]$ & 44.32 & 87.10 & 33.28 & 37.79 & 67.00 & & \\
\hline 5th $50 \mathrm{~m} \mathrm{~T} 1[\mathrm{~s}]$ & 46.44 & 88.79 & 35.76 & 38.52 & 69.54 & \multirow{2}{*}{-3.9} & \multirow{2}{*}{0.002} \\
\hline 5th $50 \mathrm{~m} \mathrm{~T} 2[\mathrm{~s}]$ & 44.20 & 85.38 & 33.36 & 37.70 & 66.90 & & \\
\hline 6th $50 \mathrm{~m} \mathrm{T1}$ [s] & 46.54 & 85.29 & 34.86 & 37.91 & 66.18 & \multirow{2}{*}{-3.0} & \multirow{2}{*}{0.01} \\
\hline 6 th $50 \mathrm{~m} \mathrm{T2}[\mathrm{s}]$ & 43,30 & 83,89 & 33,84 & 36,99 & 65,90 & & \\
\hline
\end{tabular}

\section{Discussion}

For many years, disabled swimming was treated primarily as an alternative form of rehabilitation. This was due to ignorance of the needs and abilities of disabled people. However, the last decade of the twentieth century and modern times have been the time of professional development of disabled people's swimming. It triggered research on functional capabilities of people with disabilities, and improving the training process went well beyond the aspects of rehabilitation. It can therefore be assumed that disabled swimming walks the path marked out by able-bodied swimming [14]. It is not exactly known which aspects of the discipline are at the same level today and yet to be implemented.

Swimmers with a loco-motor disability competing at the Paralympic level have been found to exhibit some similar patterns of the stroke rate and the race speed patterns $[15,16]$, whilst other components such as start, turn and finish times differ when compared to the higher swimming velocity of Olympic swimmers [17]. Other research on elite well-trained swimmers has found differences in the index of coordination [18], when comparing able-bodied swimmers to swimmers with a disability.

Disabled swimmers' training effectiveness depends largely on the rational and optimal adjustment to an individual athlete's functional capabilities. However, the development of optimal training programs needs to take account of other factors, among which knowledge of exercise metabolism and choosing the right loads become paramount [19]. 
To our knowledge there is no literature on changes in aerobic and anaerobic endurance depending on the period of training of disabled swimmers. Changes in aerobic endurance were determined by checking the difference in the covered distance between the second and the first T-30 test. The longer the distance covered, the higher the level of aerobic endurance. Based on these results, it is presumed that the level of aerobic endurance has increased, as confirmed by the results of statistical analysis. As pointed out by many scientific publications, aerobic endurance is the basis to develop other, more specific to the discipline, physiological capabilities, including special endurance. Its development and monitoring is one of the fundamental tasks of training [13, 20]. Determination of the aerobic endurance level is also a factor in a diagnosis of athlete's preparation to take specialized training aimed at the best possible preparation for a particular competition [21, 22].

Ten disabled athletes swam a longer distance in the second attempt (DST2) relative to the first sample (DST1), reflecting the increasing aerobic endurance in the sub-period of special preparation. This is confirmed by observations of other authors which were performed on swimmers without disabilities $[23,24]$. But to say that the training loads used in disabled swimmers' training in the subperiod of special preparation increased aerobic endurance in the same way as in training of ablebodied swimmers, research should be supplemented by a group of able-bodied athletes.

Aspenes et al. [25] studied the effect of strength and endurance combined training in competitive swimmers. A combined intervention of maximal strength and high aerobic intensity interval endurance training 2 sessions per week over 11 weeks in addition to regular training were used, while the control group continued regular practice with their respective teams. The intervention group improved land strength tethered swimming force and $400 \mathrm{~m}$ freestyle performance more than the control group but did not improve peak oxygen uptake. A more likely explanation is that an average of two interval-sessions a week is an insufficient stimulus to produce detectable training adaptations in competitive swimmers. Faude et al. [26] have investigated traditional high training volumes versus high intensity training of lower volume. They concluded that there seem to be no benefits of high volume compared to high intensity. $\mathrm{VO}_{2 \max }$ due to the difficulty of its measurement is rarely used to assess swimmers' aerobic capacity. Garatachea et al. [27] propose using a more practical indicator, which is the critical swimming velocity (CSV), defined as the theoretical maximal swimming velocity that could be maintained for a long period of time without exhaustion. They indicate that CSV corresponds with the OBLA (onset of blood lactate accumulation) intensity and therefore the simple method for CSV calculation is valid to plan a training schedule for physically disabled swimmers. CSV could be utilized to prescribe a specific swimming pace in order to improve the anaerobic threshold. CSV may be adopted as a valuable index for indicating swimming endurance performance without blood sampling and without employing highly expensive equipment in elite physically disabled swimmers.

Similar changes were observed in the level of anaerobic endurance, which in a sub-period of special preparation rose among all swimmers, as they all overcame distances of 50 meters faster in the second trial. By analyzing the time to overcome each of the six $50 \mathrm{~m}$ laps, you can see that it was getting longer. Speed is high in the early stages of a race before it decreases in the latter stages as swimmers fatigue [28, 29, 30].

\section{Conclusions}

In conclusion, it can be said that the applied training loads in swimmers with disabilities increased both aerobic and anaerobic endurance, and the T-30 and $6 \times 50 \mathrm{~m}$ tests seem to be simple and sensitive tools to apply in practice in order to evaluate these symptoms of disabled athletes' performance. Surely it would be beneficial in the future to also analyze parameters such as stroke length, stroke rate, heart rate or blood lactate level, as well as conducting research on a larger group of disabled swimmers.

\section{References}

1. Banister EW. Modeling elite athletic performance. In: MacDougall JD, Wenger HA, Green HJ, editors. Physiological testing of the high-performance athlete. Champaign IL: Human Kinetics Books; 1991, 403-424. 
2. Barden JM, Kell RT. Relationships between stroke parameters and critical swimming speed in a sprint interval training set. J Sports Sci 2009;27(3):227-235.

3. Zamparo $P$, Capelli $C$, Cautero $M$, Di Nino A. Energy cost of front crawl swimming at supramaximal speeds and underwater torque in young swimmers. Eur J Appl Physiol 2000;83:487-491.

4. Zamparo P, Capelli C, Pendergast D. Energetics of swimming: a historical perspective. Eur J Appl Physiol 2011;111:367-378.

5. di Prampero PE. Factors limiting maximal performance in humans. Eur J Appl Physiol 2003;90:420-429.

6. Wakayoshi K, D'Acquisto LJ, Troup JP. Relationship between metabolic parameters and stroking technique in front crawl. In: Strass D, Trappe SW, Cappaert JM, Trappe TA, editors. VII International Symposium on Biomechanics and Medicine in Swimming, Atlanta, 18-23.10.1994. London: E\&FN Spon; 1996, 152-158.

7. Pheasey C. Sport science and medicine support for British Paralympic swimmers. SportEX Med 2005;25:6-9.

8. Bompa T, Haff G. Periodization. Theory and methodology of training. Champaign, III: Human Kinetics; 2009.

9. Maglischo EW. Swimming fastest. Champaign, III: Human Kinetics; 2003.

10. Costill DL. Effects of repeated days of intensified training on muscle glycogen and swimming performance. Med Sci Sports Exerc 1998;20:249-254.

11. Jeffrey J, Bauerle J. Benefits of balanced training. Swim Tech 2004;41:10.

12. Draper J, Minikin B, Telford R. Specific Guidelines for the Physiological Assessment of the Elite Athlete. Test Methods Manual. Belconnen: Australian National Sports Research Centre; 1998.

13. Pyne D. Monitoring seasonal and long term changes in test and competitive performance elite swimmers. Australian Coaches Swimming Association; 2006.

14. McCann C. Sports for the disabled: the evolution from rehabilitation to competitive sport. $\mathrm{Br} J$ Sports Med 1996;30:279-280.

15. Daly D, Djobova S, Malone L, Vanlandewijck Y, Steadward R. Swimming Speed Patterns and Stroking Variables in the Paralympic 100-m Freestyle. Adapt Phys Act Q 2003;20:260-278.

16. Burkett B, Mellifont R. Sport Science and Coaching in Paralympic Swimming. Int J Sports Sci Coach 2008;3(1);105-112.

17. Daly D, Malone L, Smith DJ, Vanlandewijck Y, Steadward R. The Contribution of Starting, Turning, and Finishing to Total Race Performance in Male Paralympic Swimmers. Adapt Phys Act Q 2001;18:316-333.

18. Satkunskiene D, Schega L, Kunze K, Birzinyte K, Daly D. Coordination in Arm Movements During Crawl Stroke in Elite Swimmers with a Loco-Motor Disability. Hum Movement Sci 2005;24:54-65.

19. Toussaint HM, Hollander AP. Energetics of Competitive Swimming: Implications for training Programmes. Sport Med 1994;18(6):384-405.

20. Costill DL, Fielding RA, Fink WJ, King DS, Hargreaves M, Kovaleski JE. Effect of carbohydrate feeding frequencies and dosage on muscle glycogen use during exercise. Med Sci Sports Exerc 1985;17(4):456-472.

21. Deminice R, Papoti M, Zagatto AM. Prado MV. Validity of 30 minutes test (T-30) in aerobic capacity, stroke parameters and aerobic performance determination of trained swimmers. Rev Bras Med Esporte 2007;13(3):173-176.

22. Olbrecht J, Mader A. The relationship to lactic acid to long-distance swimming and the $2 \times 400 \mathrm{~m} \mathrm{2-}$ speed test and the implication for adjusting training intensities. In: Swimming Science V; Human Kinetics 1988, 261-267.

23. Sanders RH. New analysis procedures of giving feedback to swimming coaches and swimmers. In: $X X$ Internationals Symposium on Biomechanics in Sport-Swimming, University of Extramedura, Spain; 2002, 1-14.

24. Smith DJ. Performance evaluation of swimmers: scientific tools. Sports Med 2002;32:539-554.

25. Aspenes S, Kjendlie PL, Hoff J, Helgerud J. Combined strength and endurance training in competitive swimmers. J Sports Sci Med 2009;8:357-365.

26. Faude O, Meyer T, Scharhag J, Weins F, Urhausen A, Kindermann W. Volume vs. intensity in the training of competitive swimmers. Int J Sports Med 2008;29:906-912.

27. Garatachea N, Abadía O, García-Isla FJ, Sarasa FJ, Bresciani G, González-Gallego J, De Paz JA. Determination and validity of critical swimming velocity in elite physically disabled swimmers. Disabil Rehabil 2006;28(24):1551-1556.

28. Seifert L, Boulestelx L, Carter M, Chollet D. The spatial-temporal and coordinative structures in elite male 100-m front crawl swimmers. Int J Sports Med 2005;26:286-293.

29. Fulton SK, Pyne DB, Burkett B. Quantifying freestyle kick-count and kick-rate patterns in Paralympic swimming. J Sports Sci 2009;27(13):1455-1461.

30. Figueiredo P, Zamparo P, Sousa A, Vilas-Boas JP, Fernandes RJ. An energy balance of the $200 \mathrm{~m}$ front crawl race. Eur J Appl Physiol 2011;111:767-777. 